Revista de la red interuniversitaria de estudios sobre las literaturas rioplatenses contemporáneas en Francia

$12 \mid 2015$

Prodigios borgeanos: ficciones, historias, teologías

\title{
Ficciones de la conjetura. La nación como invención en Borges
}

Mariela Blanco

(2) OpenEdition

Journals

Edición electrónica

URL: http://journals.openedition.org/lirico/1916

DOI: 10.4000/lirico.1916

ISSN: 2262-8339

Editor

Réseau interuniversitaire d'étude des littératures contemporaines du Río de la Plata

Referencia electrónica

Mariela Blanco, «Ficciones de la conjetura. La nación como invención en Borges », Cuadernos LIRICO [En línea], 12 | 2015, Puesto en línea el 23 enero 2015, consultado el 01 mayo 2019. URL : http:// journals.openedition.org/lirico/1916 ; DOI : 10.4000/lirico.1916

Este documento fue generado automáticamente el 1 mayo 2019.

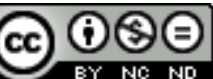

Cuadernos LIRICO está distribuido bajo una Licencia Creative Commons Atribución-NoComercialSinDerivar 4.0 Internacional. 


\title{
Ficciones de la conjetura. La nación como invención en Borges
}

\author{
Mariela Blanco
}

Conjeturé que ese país indocumentado y ese heresiarca anónimo eran una ficción improvisada por la modestia de Bioy para justificar una frase. El examen estéril de uno de los atlas de Justus Perthes fortaleció mi duda. "Tlön, Uqbar, Orbis Tertius"

\section{¿Nacionalizar la imaginación o imaginar la nación ?}

1 Si bien ya hace un tiempo que los críticos han logrado discutir y revertir la asociación entre la obra de Borges y su carácter irreal, demostrando la importancia que los datos históricos cobran en su obra, así como las alusiones más o menos directas al contexto de enunciación, considero que aún queda un vasto territorio por explorar en pos de explicar el sustrato ideológico que subyace en esas marcas de la historia. En este trabajo, a partir del análisis de "Funes el memorioso" y "La forma de la espada", me propongo demostrar que la manera lúdica, tendiente a la imprecisión en la que se presentan los cronotopos, obedece a un dispositivo ideológico : el de resaltar el carácter convencional de cualquier invención humana, entre las que se destacan las formas de orden social y político aludidas de manera indirecta (Kaplan 1984 : 329). De este modo, la escritura de Borges se recorta como un campo de batalla desde el cual cuestionar una de las más fuertes y arraigadas construcciones simbólicas de la modernidad, la idea de nación, a través de la imaginación de ficciones conjeturales.

2 En los últimos años, Benedict Anderson, en su célebre Imaginated Communities, enfatizó el carácter imaginario de la idea de nación (6-7), mientras Homi Bhabha -continuando esta línea de análisis - hizo hincapié en su naturaleza narrativa (Bhabha 2000 : 211). Sostengo que Borges ya en los 40 esgrimió estos conceptos en clave ficcional en los cuentos de 
Ficciones, entablando una clara polémica con los discursos nacionalistas en boga en el período, focalizados en cimentar las bases de la idea de nación como unidad esencial y homogeneizante.

3 Hablo de "ficciones conjeturales" porque estas narraciones se articulan sobre procedimientos discursivos que, lejos de proponer coordenadas tempo-espaciales precisas, postulan varias posibilidades para definir sus contornos. De este modo, en los relatos de Borges se construyen mundos posibles, irrealizables en apariencia, a partir de dispositivos narrativos simulados por un "como si" que hace explícito el pacto ficcional con el lector. Así, se multiplican los universos posibles en donde las acciones tienen lugar. Estas distopías (Sarlo 2001: 56) se convierten en un recurso más para enriquecer la ideología sobre lo nacional que estos textos trasuntan. Por eso, sostengo que la escritura de Borges, en sus distintos géneros, tiene como rasgo saliente la postulación de realidades ideales, potenciales, con el objetivo de satirizar el orden indeseable de la sociedad conocida o cercana al lector.

Se trata de la puesta en ficción del mecanismo tanta veces ponderado por el autor en sus ensayos ("La flor de Coleridge", "Magias parciales del Quijote", entre otros), y que las teorías posestructuralistas han denominado como metaficción, a través del cual una ficción dentro de otra desencadena un efecto de refracción infinito. En clara polémica con el realismo imperante en la literatura argentina del momento, la escritura de Borges propone que la puesta en evidencia del artificio literario constituye el mejor vehículo para representar el mundo en la literatura. Esta lectura permite recorrer toda su producción debido a que el concepto de "invención" se encuentra presente desde sus primeros poemarios hasta sus últimos relatos ${ }^{1}$. El idealismo de Berkeley es el modelo filosófico más evidente de este ideario que Borges transforma en motor de sus ficciones.

Balderston, en su libro ¿Fuera de contexto ? (1996), polemizó con Barrenechea demostrando que hay más realidad que irrealidad en las ficciones de Borges. El punto de partida de este artículo es el análisis de la manera en que se introducen las referencias temporales y espaciales ${ }^{2}$. En efecto, cuando este crítico discute con estudiosos anteriores, trae a colación no solo la importancia del contexto, sino que rescata las especulaciones sobre el carácter conjetural de estas ficciones. Éstas iban orientadas a resaltar la irrealidad de la obra de Borges, en el sentido de desvinculación con lo real. En este trabajo se demostrará que ambas perspectivas se integran, pues son ficciones conjeturales, pero su función -como anticipa Balderston en su importante lectura- es resaltar la relación con el contexto en una dirección contraria a la del realismo. El contexto es un material, un eco, que ingresa al mundo ficcional y, por refracción, se subraya su carácter artificialconvencional, tanto como el de la ficción (Balderston 1996 : 17). Cualquier sistema creado por el hombre, cualquier lenguaje, es convencional y artificial. La idea de nación lo es y eso supone un debate en una época en donde los nacionalismos o el sentimiento nacionalistas de las grandes potencias estaban exacerbados en el clima de preguerra. Una de las mejores bromas que satiriza esta situación se encuentra en « Pierre Menard, autor del Quijote ", cuando el narrador señala que la reescritura de Menard "Desatiende o proscribe el color local » (OC I : 448) al escribir en el español de Cervantes en el contexto francés de fines del XIX. El cuento más alegórico de todos, en este sentido, es « La lotería en Babilonia ", donde la trama es una indagación sobre el orden social de una sociedad ficticia, pero con muchas resonancias respecto de modos de organización política conocidos. Mi análisis no se detendrá especialmente en estos relatos porque ya han sido tratados vastamente por la crítica. Señalo solamente una referencia que presenta este 
modo alegórico de hacer resonar el mundo real: "En segundo término, logró que la lotería fuera secreta, gratuita, general” (OC I : 458), bajo la cual resuena la ley Sáenz Peña, que instituyó el voto "universal, secreto y obligatorio" para los varones nativos o naturalizados y mayores de 18 años en Argentina a partir de 1912. Añado un escrito borgeano, no tan conocido, pero del mismo año 1942 de los cuentos que abordaré, en donde, a partir del análisis de una alegoría china, Borges propone :

J. M. Robertson, en su Breve historia del Cristianismo, sugiere que los gnósticos delinearon las jerarquías divinas a imagen de la burocracia terrestre; los chinos han usado ese método : Wu Ch'eng-en satiriza con fruición la burocracia angelical y, por consiguiente, la de este mundo. (Borges 2007 : 199)

6 La hipótesis de lectura que propongo se encuentra esbozada en el prólogo a Artificios, la segunda parte que conforma el volumen Ficciones, que se adosa a El jardín de senderos que se bifurcan, publicado previamente en 1941.

La primera ["La muerte y la brújula], pese a los nombres alemanes o escandinavos, ocurre en un Buenos Aires de sueños : la torcida Rue de Toulon es el Paseo de Julio; Triste-le Roy, el hotel donde Herbet Ashe recibió, y tal vez no leyó, el tomo undécimo de una enciclopedia ilusoria. Ya redactada esa ficción, he pensado en la conveniencia de amplificar el tiempo y el espacio que abarca. (OC I : 483)

7 Esa amplificación es precisamente la que analizaré, proponiendo que redunda en una difuminación de los límites nómino tempo-espaciales que cuestiona las creencias difundidas por los discursos nacionalistas en torno de la idea de nación.

\section{Enunciar, nombrar, hablar de la nación}

Respecto de este procedimiento que intentaré caracterizar, no resulta casual que haya similitudes estructurales entre "Funes el memorioso" y "La forma de la espada", ya que los dos relatos fueron publicados en 1942 en un lapso de un mes y medio ${ }^{3}$. Además, el cuento citado arriba, "La muerte y la brújula", data del mismo año, de lo que puede inferirse que este juego con los dispositivos locativos y temporales, así como las elecciones de nombres propios, constituyó una preocupación para el escritor en este período.

9 Ambos cuentos están presentados por un narrador testigo que cede su voz para narrar la historia de un interlocutor con algún rasgo distintivo que hace que sea válido que el protagonismo de esa primera persona pase a segundo plano. En el primer caso, en estilo indirecto; en el segundo, en estilo directo. No obstante, antes de centrarme en las características de estos personajes protagonistas, quiero detenerme en aquellos rasgos de los narradores esbozados como al pasar que se repiten en ambos cuentos.

En "Funes el memorioso", el narrador evoca al personaje del cual dará testimonio y que pasará a integrar un volumen que reunirá escritos de "todos aquellos que lo conocieron" ( $O C$ I : 485). En efecto, "lo recuerdo" es el sintagma que inicia el cuento y que se repite anafóricamente en el mismo párrafo cuatro veces más. Esta memoria está enmarcada entonces como un relato al modo epistolar, pues hay una segunda persona ("del volumen que editarán ustedes" $O C \mathrm{I}: 485$ ), sin dilucidar siquiera si se trata entonces de un esbozo o primera versión de lo que será luego una versión definitiva o si lo que sigue luego de este encuadre efectivamente lo es. Pero lo que más interesa de este primer párrafo que sirve de marco es la semblanza que, como al pasar, da la primera persona de sí mismo, obliterada por la del protagonista, el sujeto del homenaje : 
Me parece muy feliz el proyecto de que todos aquellos que lo trataron escriban sobre él ; mi testimonio será acaso el más breve y sin duda el más pobre, pero no el menos imparcial del volumen que editarán ustedes. Mi deplorable condición de argentino me impedirá incurrir en el ditirambo -género obligatorio en el Uruguay, cuando el tema es un uruguayo. Literato, cajetilla, porteño; Funes no dijo esas injuriosas palabras, pero de un modo suficiente me consta que yo representaba para él esas desventuras. Pedro Leandro Ipuche ha escrito que Funes era un precursor de los superhombres, "un Zarathustra cimarrón y vernáculo"; no lo discuto, pero no hay que olvidar que era también un compadrito de Fray Bentos, con ciertas incurables limitaciones. (OC I : 485 ; énfasis en el original)

11 Este enunciado no sólo hace gala de la necesaria "falsa modestia" requerida por las introducciones de este tipo, sino que constituye una justificación de la pretendida imparcialidad, que - aunque o precisamente por estar mitigada por la falsa negación- se convierte en un valor para el narrador. En este sentido, se destaca la adversativa que confronta la presuntuosa afirmación atribuida a Ipuche -primer nombre con referente real- en la que el "no hay que olvidar", más allá de su valor imperativo, funciona como una variante del "recuerdo" antes aludido.

De modo que no resulta para nada menor este dato de la "deplorable condición de argentino" del narrador, ya que de ahí deriva el tono, el enfoque, la singularidad del punto de vista de su testimonio, diferente, cuando menos, al de los uruguayos ${ }^{4}$. Algo similar se observa en "La forma de la espada": "Acudí a la menos perspicaz de las pasiones : el patriotismo" (OC I : 491). En este caso, no importa tanto la nacionalidad del enunciador, cuanto el concepto de patriotismo como dispositivo que sirve para que se produzca el grado de acercamiento necesario que desencadena la confesión en primera persona del protagonista. El acto de ceder la voz es aún más claro en este caso, pero, para que éste se produzca, esta breve digresión sobre el origen de los personajes parece necesaria. Incluso hay una inflexión de este encuentro que lo hace más profundo aún, no dado por el diálogo, pero sí por la procedencia nacional. En efecto, el vínculo previo a la confesión del personaje que será presentado como "el Inglés" se produce cuando ambos personajes, luego de haber bebido "largamente en silencio" salen a mirar "el cielo", la inmensidad que los hermana, pero connotada por un punto cardinal : "Había escampado, pero detrás de las cuchillas el Sur, agrietado y rayado de relámpagos, urdía otra tormenta" (OC I : 491). Vale recordar que esta cita es crucial dentro de la presentación de la trama que vendrá, funcionando por tanto como una alusión alegórica de un relato atravesado por la violencia de una guerra cuyo marco predilecto es el sur. Este dato resultaría menor de no tener correlato con tantos otros textos borgeanos, desde sus primeros escritos. Tal es el caso del cuento homónimo, en donde el sur es el espacio del sueño, de la imaginación, que alberga personajes del pasado, ese "Sur que era suyo" (OC I : $528)^{5}$. Si el sur es, para el Borges de los primeros tres poemarios y ensayos, una sinécdoque de la pampa, de este arrabal, de "algún estado sudamericano", de la Argentina como patria a la que hay que inventarle un programa literario, en estos relatos, cuando menos, parece ampliar sus contornos para decir algo más.

13 Un pasaje clave para leer esta reinterpretación del sur se encuentra en "Tlön, Uqbar, Orbis Tertius", que sintetiza el carácter metafórico de los nombres propios de la historia, así como el tono nebuloso, arbitrario, de las referencias que definen una frontera. ¿Una zona imaginaria? Posiblemente, pero que sin dudas refracta sobre todas las comunidades imaginarias que damos en llamar naciones modernas. Vemos el pasaje, seguido de la 
mención de otras "regiones imaginarias", pues ¿cómo definir los contornos de un territorio si no es en relación de contraste con otros?:

De los catorce nombres que figuraban en la parte geográfica, sólo reconocimos tres -Jorasán, Armenia, Erzerum-, interpolados en el texto de un modo ambiguo. De los nombres históricos, uno solo : el impostor Esmerdis el mago, invocado más bien como una metáfora. La nota parecía precisar las fronteras de Uqbar, pero sus nebulosos puntos de referencias eran ríos y cráteres y cadenas de esa misma región. Leímos, verbigracia, que las tierras bajas de Tsai Jaldún y el delta del Axa definen la frontera del sur y que en las islas de ese delta procrean los caballos salvajes. (OC I : 432)

Reconsiderando el programa de ampliación de los límites espaciales central en la poética del período recortado, se observa que en los textos que integran el volumen, situar espacialmente el relato, resulta una convención externa de la que el autor se burla sutil pero efectivamente en cada uno de los textos con leves variantes.

\section{Nacionalidad : indeterminación y secreto}

Respecto de las voces de "La forma de la espada", el acercamiento al personaje a quien el narrador cederá inmediatamente la voz se produce por una alusión a la nacionalidad del interlocutor. Al respecto, se advierte una búsqueda deliberada de confusión con las nacionalidades de los personajes en estos relatos, que leo como un desafío a los afanes homogeneizantes que singularizan a los discursos nacionalistas. Sobresale la presunción y la consiguiente corrección del equívoco del Inglés cuando revela ser irlandés. Detengámonos en el sintagma que sigue, donde se advierte la importancia de lo que podría parecer un detalle : "Dicho esto se detuvo, como si hubiera revelado un secreto" ( OC I : 491). Señalo la constante del procedimiento en muchos de los cuentos del volumen para enfatizar que la confusión no es sólo importante en función de la trama del cuento (la guerra irlandesa por la independencia, que coloca al personaje en las antípodas de su identidad asumida por los habitantes de Tacuarembó), sino también como ideologema que subvierte la noción misma de nacionalidad al presentarla como una construcción imaginaria, más allá de su constatación en el plano de lo real. En síntesis, una invención basada en un pacto, en una creencia compartida, convencional. El segundo enunciado del cuento lo ratifica : "Su nombre verdadero no importa : todos en Tacuarembó le decían el Inglés de La Colorada" (OC I : 491 ; énfasis mío).

El poder de la invención por sobre el mundo real, base del programa poético de Borges, se condensa en la posdata de "Tlön, Uqbar, Orbis Tertius", donde "la primera intrusión del mundo fantástico en el mundo real" se constata - nuevamente - "hacia 1942" (aunque el cuento haya sido publicado en 1940) a través de la intromisión de objetos de este planeta imaginario en el "mundo real" modelado por el escritor con la introducción de nombres propios constatables, como el suyo y el de Bioy, por citar los ejemplos más obvios. Vale enfatizar la ¿coincidencia?: una de esas intromisiones se sitúa en la "Cuchilla Negra", cordillera uruguaya lindante con Brasil, debido a una crecida del río Tacuarembó.

En este punto, resalto la importancia de las repeticiones de palabras en los dos cuentos tratados. La economía del estilo de estas narraciones ya ha sido subrayada en demasía. Baste aquí señalar nuevamente que si una palabra se repite es para establecer un link que deja entrever el poder de condensación de los vocablos. Tal es el caso del secreto en "La forma de la espada", que tiene el poder de la confesión cuando es develada al narrador, 
como ya mencioné respecto del sintagma "como si hubiera revelado un secreto", pero que previamente tiene el poder de hacer cambiar de opinión al dueño de la estancia $L a$ Colorada, quien antes de escuchar "la historia secreta de la cicatriz" no quería vender la estancia ${ }^{6}$.

Es precisamente este secreto sobre el origen el que dispara las especulaciones, las conjeturas de los habitantes de la zona, quienes cobran relevancia por sus decires, condensados en el primer párrafo del cuento. Antes de la irrupción de la primera persona, es a través de este consenso que se presenta al Inglés : “...todos en Tacuarembó le decían el Inglés de La Colorada. [...] no faltó quien dijera que en el Brasil había sido contrabandista. [...] Dicen que era severo hasta la crueldad, pero escrupulosamente justo. Dicen también que era bebedor " (OC I : 491 ; énfasis mío).

Nacionalidad, origen, marca identitaria cuyos límites se difuminan también en "Funes el memorioso". Recordemos el intento de definición de Ipuche y la consiguiente relativización del narrador. Sumemos la afirmación respecto de su origen : "Agregó que era hijo de una planchadora del pueblo, María Clementina Funes, y que algunos decían que su padre era un médico del saladero, un inglés O'Connor, y otros un domador o rastreador del departamento del Salto" (OC I : 486; énfasis mío). No escapa la repetición de la asimilación inglés-irlandés, similar al otro cuento, si reparamos en que el apellido aludido tiene una inconfundible reminiscencia irlandesa ${ }^{7}$. Tampoco la repetición del verbo "decir" con matiz impersonal, tal como enfaticé en la última cita de "La forma de la espada".

Así, el origen de los personajes se presenta a partir de la incertidumbre, haciendo énfasis en el acuerdo de "todos" o "algunos" que asignan una nacionalidad a partir de presunciones que resultan subrepticiamente cuestionadas luego de su enunciación. Lo más interesante es la insistencia del enunciador en la poca importancia del dato, pues no creo que el juego con la confusión de apellidos u otros rasgos resulte inocente. Los dos niveles del discurso que se instalan permiten advertir el espesor paródico de estos textos, en donde el objeto de la mirada dialógica lo constituyen los discursos nacionalistas imperantes en el imaginario social del momento, tal como he intentado demostrar en artículos anteriores (Blanco 2011 y 2013).

Detengámonos nuevamente en el Inglés, cuyo "nombre verdadero no importa", una vez que ya sabemos que es irlandés y que develamos, al final, que su historia es la de John Vincent Moon. "En un atardecer que no olvidaré, nos llegó un afiliado de Munster : un tal John Vincent Moon", dice el mismo traidor y héroe para introducirlo en su historia. Respecto de la elección del nombre, conocemos la fascinación de Borges por la palabra "moon" por su eficacia fónica, a la que se le agrega la semántica en este texto : "con esa media luna de acero le rubriqué en la cara, para siempre, una media luna de sangre" ( $O C$ I : 494).

22 Vale detenerse también en el momento del día en el que el personaje irrumpe, significativo en cuanto, al igual que el amanecer, está signado por la transición, la indefinición. En este sentido, hay una evidente continuidad respecto del Borges poeta de los primeros poemarios, en donde amaneceres y atardeceres son parte del objeto imaginario que la mirada recorta en su construcción de la ciudad-patria imaginada.

23 Por otro lado, ¿puede haber una forma más efectiva de despersonalizar un nombre que a través de ese "un tal" ? Esta forma de presentación del nombre propio suena como una convención más, una repetición del acuerdo narrativo conjetural explicitado de manera 
paradigmática en el comienzo de "Tema del traidor y del héroe": "Digamos Irlanda, digamos 1824" (OC I : 496), solo importante para el recuerdo del personaje, para su versión de los hechos ${ }^{8}$; por eso: "En un atardecer que no olvidaré, nos llegó un afiliado de Munster..." (OC I : 492), en donde las primeras personas del singular y el plural enfatizan el matiz subjetivo de la versión de los hechos. Unos pocos años después, en "El pudor de la historia" (1952), Borges sintetizará esta concepción de la historia como relato secreto, cifrado en detalles que -por su anomalía- pueden pasar inadvertidos (OC II : 132).

Tal como en "Funes el memorioso", donde se metaforizan los mecanismos selectivos que condicionan nuestro conocimiento del mundo a partir de la figura hiperbólica y deformante de su opuesto (que no distingue diferencias y, por tanto, no es capaz de generalizar), en estos cuentos abundan las operaciones de selección a las que obliga la escritura de la historia. Estos relatos, en donde el juego con los hechos de la historia es evidente, se presentarían como una forma de venir a cubrir ese vacío oponiendo otras versiones posibles de los acontecimientos. Pero destaco que no se trata de una contrahistoria, sino de un cambio de foco, erigido en torno a una apariencia de azar y conjetura que expande, a partir de algún punto, otras posibilidades de los relatos, enfrentando y haciendo proliferar versiones cuyo único anclaje es la expansión de una de las tantas posibilidades que deja abierta el relato de base.

El mecanismo también se advierte tempranamente en "La penúltima versión de la realidad" (1928) ya a través sólo del título, que sugiere que no hay una sola versión de la realidad, sino infinitas posibilidades de relatos que den cuenta de ella, especialmente a partir de la imaginación, motor de todo relato (de la realidad, de la ficción, sin distinción ninguna en este sentido). La puesta en práctica narrativa es clara en la mayoría de los cuentos del volumen; tal es el caso de "Examen de la obra de Herbert Quain", autor célebre por la puesta en práctica de este procedimiento, y de "Tres versiones de Judas". Una de las claves metapoéticas de esta operación por la cual los personajes, en su singularidad, son cifra de la trama secreta de la historia, se condensa en la siguiente reflexión de Yu Tsun, en "El jardín de senderos que se bifurcan" : "Después reflexioné que todas las cosas le suceden a uno precisamente, precisamente ahora. Siglos de siglos y sólo en el presente ocurren los hechos ; innumerables hombres en el aire, en la tierra y el mar, y todo lo que realmente pasa me pasa a mí ..." (OC I : 472). En el marco de uno de los cuentos en donde el contexto opresivo y de violencia enmarcada en la Segunda Guerra Mundial es más evidente, propongo que debajo de este enunciado subyace algo más que una versión distinta de los hechos. Lo más importante es desentrañar uno de los ideologemas distintivos de "Nuestro pobre individualismo" (1946), aquél que propugna la primacía del individualismo del carácter argentino, que se presenta con visos descriptivos, pero adquiere más el carácter de proclama en el contexto político tanto internacional como nacional. Se trata de la defensa del individuo por sobre el cuerpo social, de cuño liberal. De este modo, los personajes, lejos de ser transmisores de valores representativos, se presentan como cifra de un destino singular, frente a la imposición de los límites fijados por los sistemas totalitarios del momento. Por eso, justamente Yu Tsun, espía chino, a las órdenes del gobierno alemán, acosado por otro espía irlandés que responde a los intereses ingleses, reflexiona sobre el origen de las guerras cuando logra suspender precisamente las coordenadas de espacio y tiempo (como Hladík en "El milagro secreto") :

Pensé en un laberinto de laberintos, en un sinuoso laberinto creciente que abarcara

el pasado y el porvenir y que implicara de algún modo los astros. Absorto en esas 
ilusorias imágenes, olvidé mi destino de perseguido. Me sentí, por un tiempo indeterminado, percibidor abstracto del mundo. El vago y vivo campo, la luna, los restos de la tarde, obraron en mí; asimismo el declive que eliminaba cualquier posibilidad de cansancio. La tarde era íntima, infinita. El camino bajaba y se bifurcaba, entre las ya confusas praderas. Una música aguda y como silábica se aproximaba y se alejaba en el vaivén del viento, empañada de hojas y de distancia. Pensé que un hombre puede ser enemigo de otros hombres, de otros momentos de otros hombres, pero no de un país; no de luciérnagas, palabras, jardines, cursos de agua, ponientes. (OC I : 475) pertenecer a un territorio al que se le atribuyen características determinantes para aquellos individuos que integran ese conjunto imaginario, tales como la lengua. Mucho antes que las teorías poscoloniales, Borges, a través de estos mecanismos que descentran las coordenadas temporales y espaciales respecto del origen de sus personajes, pone en evidencia el carácter imaginario y, por ende, arbitrario y artificial de este constructo. Resulta clave, en ese sentido, "La secta del Fénix", cuento agregado al volumen en $1956^{9}$. En pos de dar cuenta de lo que une a los miembros de la secta, el investigador narrador descarta una a una las probables variables cohesivas más comúnmente atribuidas a una nación, llegando a concluir el vaciamiento de sentido del sustento ideológico de la propia secta, que se reduce así a mero resto, el rito, repetitivo y sin sentido, "instintivo" :

Sin un libro sagrado que los congregue como la Escritura a Israel, sin una memoria común, sin esa otra memoria que es un idioma, desparramados por la faz de la tierra, diversos de color y de rasgos, una sola cosa -el Secreto- los une y los unirá hasta el fin de sus días. Alguna vez, además del Secreto hubo una leyenda (y quizá un mito cosmogónico), pero los superficiales hombres del Fénix la han olvidado y hoy sólo guardan la oscura tradición de un castigo. De un castigo, de un pacto o de un privilegio, porque las versiones difieren y apenas dejan entrever el fallo de un Dios que asegura a una estirpe la eternidad, si sus hombres, generación tras generación, ejecutan un rito. (OC I : 522)

Otra de las estrategias salientes es la indeterminación de sus características, el regodeo con los oxímoron, que da cuenta nuevamente de la elección por las zonas fronterizas, borrosas. Tomo como ejemplo esta breve semblanza de Moon :

Tenía escasamente veinte años. Era flaco y fofo a la vez; daba la incómoda impresión de ser invertebrado. Había cursado con fervor y con vanidad casi todas las páginas de no sé qué manual comunista; el materialismo dialéctico le servía para cegar cualquier discusión. Las razones que puede tener un hombre para abominar de otro o para quererlo son infinitas : Moon reducía la historia universal a un sórdido conflicto económico. (OC I : 492)

30 Cada uno de los enunciados de este fragmento puede leerse en función de una búsqueda de la atenuación de cualquier afirmación tajante : el adverbio "escasamente" mitiga la afirmación sobre la edad ; la conjunción de "flaco" y "fofo" marca una contradicción que impide la clara clasificación del personaje; se elige omitir el nombre del manual comunista con el "no sé" ; por último, el materialismo dialéctico tiene un efecto cegador. De esta relativización gradual se desprende que "abominar" y "querer" son dos caras de la misma moneda en el contexto de guerra. Aun la lengua de este traidor/héroe es indefinida : “Ésta es la historia que contó, alternando el inglés con el español, y aun con el 
portugués" (OC I : 492). Por otro lado, cabe observar la similitud del último enunciado con el de la cita anterior de "El jardín", a partir de los cuales se advierte la obsesión por indagar las causas de los enfrentamientos entre los hombres y sus naciones.

Algo similar ocurre con la breve presentación de los rasgos de "un tal Ireneo Funes" (OC I : 486). La mirada del narrador recorta -dinámica propia de la memoria, objeto del cuento ,- y lo hace desde un presente de enunciación, "hace ya medio siglo" (OC I : 487), distante respecto de los hechos referidos, es decir, aproximadamente hacia 1934.

Lo recuerdo, la cara taciturna y aindiada y singularmente remota, detrás del cigarrillo. Recuerdo (creo) sus manos afiladas de trenzador. Recuerdo cerca de esas manos un mate, con las armas de la Banda Oriental ; recuerdo en la ventana de la casa una estera amarilla, con un vago paisaje lacustre. Recuerdo claramente su voz ; la voz pausada, resentida y nasal del orillero antiguo, sin los silbidos italianos de ahora. (OC I : 485 ; énfasis en el original)

El narrador recuerda, con dudas ("creo") o no, rasgos que se difuminan "detrás del cigarrillo", o sintetiza la vaguedad del recuerdo a través de adjetivos que imprimen dosis de indeterminación al desdibujar detalles, como en "cara ... remota" y "vago paisaje". Por otro lado, ya desde estas primeras líneas se adelanta no sólo el tema del relato -la operación de selección que entrañan, en primera instancia, la percepción y luego la memoria- sino también lo que constituye uno de los preceptos narrativos de Borges, rastreable a lo largo de toda su producción. Me refiero al modo de referir por sinécdoques, que permite mostrar solo una parte, un detalle simbólico que dé cuenta de la totalidad (Blanco 2013 : 152-157).

En esta semblanza, otro aspecto que da cuenta de la perspectiva ideológica es su consideración del carácter anacrónico de Funes. El literato se detiene en lo que éste simboliza como "resto" en relación con el presente de enunciación. Así, "la voz pausada, resentida y nasal del orillero antiguo, sin los silbidos italianos de ahora", remite al contexto posinmigratorio que cambió los contornos de la lengua en el Río de la Plata y que se constituye en tema central no sólo de varios ensayos de Borges, sino de la literatura rioplatense del período. Algo similar ocurre con un objeto significativo, claro exponente de ese mecanismo asimilable al tercero esbozado en "La postulación de la realidad" : "la invención de la realidad", que se puede resumir, a partir de los ejemplos que Borges propone, como una forma de aludir a una totalidad (pertenencia social de un personaje, por ejemplo) desde sus "pormenores lacónicos" o detalles (OC II : 220). En este caso, me refiero al "mate, con las armas de la Banda Oriental", denominación territorial que reenvía a tiempos anteriores a la guerra de la independencia de Uruguay de 1830 . De este modo, la forma de presentar a Funes ofrece mucho más que un vago recuerdo, explotando esta posibilidad de expandir los límites simbólicos de unos pocos detalles.

Funes es un exponente de la nacionalidad uruguaya criolla, en extinción; el símil del "criollo viejo" que encuentra su exponente paradigmático dentro de la narrativa de Borges en la figura de don Isidro Parodi, cuyo primer volumen de la saga -así como el cuento inicial, "Las doce figuras del mundo"- se publica en el mismo año 1942. Ambos son personajes anacrónicos, fuera de lugar (uno recluido en su habitación; el otro, en la celda 273 de la Penitenciaría Nacional), dentro de los límites de las naciones del presente. A partir de esto, precisaré la hipótesis inicial de este trabajo sosteniendo que la escritura de Borges del período no se opondría a la idea esencial de nación, sino a una de sus concreciones, aquélla que a partir de 1930 (primer golpe de estado en Argentina, con apoyo de los nacionalistas) y en el mundo (contexto de entreguerras) comienza a cambiar 
claramente sus contornos. Generalizando, y siempre considerando la mirada de Borges que se desprende de sus escritos, pienso en el concepto de nación cuyo sustrato imaginario pasa a estar amenazado por la omnipresencia del modelo de estado totalitario. Esta lectura arrojaría una explicación más, otra posible, sobre la famosa disyuntiva entre los dos Borges o la existencia de un Borges criollista que súbitamente ¿mágicamente? abandona el programa, abomina de él.

Ya Barrenechea había calificado de "conjetural" esta narrativa de Borges (Barrenechea 2000 : 149-157). Coincido con esta observación, pero ahora quiero detenerme en otra derivación del calificativo, partiendo de la primera acepción que ofrece el Diccionario de la Real Academia Española, en donde la conjetura se define como "juicio que se forma de las cosas o acaecimientos por indicios y observaciones" (versión online). Hay un leve matiz en la definición que la vuelve digna de atención en relación con los juegos borgeanos: dado el carácter erróneo de estos "juicios", los mismos se convierten en pre-juicios que condicionan la identidad de los personajes. La conjetura no funciona, en este caso, del mismo modo que en el comienzo de "Tema del traidor y del héroe", como una invitación a entablar un pacto ficcional, sino como un cuestionamiento de la creencia, arraigada en el mundo externo, de la representación. El pacto ficcional aquí parecería decirnos algo como "su nombre verdadero no importa" porque es meramente convencional. Así, las marcas de verosimilización como nombres propios, fechas y espacios son corroídas, vaciadas de contenido.

Otros recursos que refuerzan el carácter conjetural son los adjetivos y los verbos a través de los cuales los narradores enmarcan los relatos. La estructura anafórica que imprime la acción de recordar en "Funes el memorioso" se repite en "La forma de la espada", con algunas variantes como "rememoro", pero nuevamente atenuadas por aclaraciones entre paréntesis del tipo "(creo recordar)" o "(con verdad)", que siembran la duda sobre la exactitud del relato. El tan mentado idealismo de Berkeley, claro, pero a la luz de la densidad de los hechos evocados, la posición metafísica se resignifica en un sentido preciso $^{10}$. Aludo a la posición escéptica no sólo respecto de las posibilidades de conocer, sino de confiar en las creencias que sustentan las mismas representaciones de la guerra, de la violencia que sirve de marco de estos textos. No de otro modo puede leerse la simbología que ofrece la repetición de la escena de los soldados borrachos disparándole a un maniquí sobre el final de "La forma de la espada". El recuerdo más "tenaz" de ese maniquí sobre el cadáver es apenas la marca a través de la cual se inscribe otra posible lectura : la del simulacro que trasciende los hechos más sangrientos de la historia. Pues las creencias que subyacen a cada guerra, considerada como punto álgido de la violencia, son igualmente imaginarias.

\section{Tiempos y espacios : un desafío a las fronteras}

La imprecisión se hace evidente también en los tiempos del relato. Así como ya destaqué la importancia de la llegada de Moon al atardecer, Funes tiene su primer encuentro con el narrador en el mismo momento del día y, luego del accidente, se refiere que "En los atardeceres, permitía que lo sacaran a la ventana" (OC I : 486).

En cuanto a las fechas, su precisión es sólo aparente. Es llamativa la predilección por momentos indefinidos, pues más allá de que hay fechas precisas, siempre alguna nota agregada difumina sus límites. En Funes, sólo se recuerdan los años, apenas los meses correspondientes a los encuentros, que constituyen el hecho referido, el hecho 
significativo de la historia. Por ejemplo : "Lo veo en un atardecer de marzo o febrero del año 84" (OC I : 485). Esta indefinición contrasta con la única fecha definida, el 14 de febrero de 1887, día que le comunican al narrador la enfermedad de su padre, que coincide - más allá de la variante del año- con el día en que muere Jorge Guillermo Borges, padre del escritor, en el año 1938.

En "La forma de la espada" el juego con las fechas es aún más elocuente, de lo que se desprende que la exactitud de los datos resulta menos interesante que sus posibilidades ficcionales, así como su asociación con la idea de definición/indefinición de los contornos de una nación. El relato del protagonista comienza con una aproximación : "Hacia 1922, en una de las ciudades de Connaught, yo era uno de los muchos que conspiraban por la independencia de Irlanda" (OC I : 492). La ubicación cronológica, si bien comienza siendo imprecisa, se vuelve más exacta más adelante, cuando fija las coordenadas de la escena final : "En aquel otoño de 1922 yo me había guarecido en la quinta del general Berkeley" ( OC I : 493), confirmando así el carácter anacrónico de los hechos y haciendo evidente el artificio, pues ¿cuáles son los motivos por los cuales Borges elige el año 1922 para ubicar el relato, cuando es en diciembre de 1921 que se firma el tratado con Inglaterra? Si bien el Estado irlandés independiente se crea el 6 de diciembre de 1921, la violencia que distingue los hechos relatados resulta un tanto anacrónica respecto de los hechos de la historia ${ }^{11}$. Otro dato que respalda esta lectura está dado por la mención de los Black and Tans, fuerza paramilitar británica, recordada por sus acciones contra la población civil, cuyas acciones habrían finalizado con la firma del tratado durante el invierno anterior al otoño referido ${ }^{12}$.

Esta imprecisión con las fechas se explica por la preeminencia de la concepción de la nación como un espacio imaginario, un sueño, tal como confiesa el protagonista :

Irlanda no sólo era para nosotros el porvenir utópico y el intolerable presente ; era una amarga y cariñosa mitología, era las torres circulares y las ciénagas rojas, era el repudio de Parnell y las enormes epopeyas que cantan el robo de toros que en otra encarnación fueron héroes y en otras peces y montañas... (OC I : 492)

41 En el mismo sentido funciona el carácter fronterizo de estos personajes en relación con el espacio. El presente de enunciación de ambos relatos está ubicado en Uruguay, en zona de estancias, es decir, en lugares en los que confluyen espacios imaginarios delimitados por los dispositivos de creencias fundacionales de nuestra cultura letrada, los de civilización y barbarie ${ }^{13}$. Así, "El Inglés venía de la frontera, de Río Grande del Sur" (OC I : 491), antes de llegar a la estancia de Tacuarembó ; mientras que la historia de Funes se ubica en Fray Bentos, zona límite entre el país vecino y la provincia argentina de Entre Ríos, aunque el encuentro con Funes se produce cerca de la estancia San Francisco, durante el regreso de una excursión del narrador y su primo ; más concretamente, en un "callejón que se ahondaba entre dos veredas altísimas de ladrillo" (OC I : 485). Si no son espacios del "entre" en sí, la mirada o el recuerdo los transforma en tales: "la única vez que lo vi, veníamos a caballo de San Francisco y él andaba en un lugar alto; el hecho, en boca de mi primo Bernardo, tenía mucho de sueño elaborado con elementos anteriores" (OC I : 486) ${ }^{14}$. Las imágenes posteriores que evoca el narrador lo presentan detrás de una ventana y de una reja, objetos también de frontera o límite, tanto espaciales como temporales.

El mismo procedimiento se observa en "La forma de la espada". Bajo un similar influjo de la magia de la evocación confusa, los espacios se presentan según la misma dinámica de amplificación difuminatoria de límites: "perplejos corredores", "vanas antecámaras", "corredores de pesadilla" y "hondas escaleras de vértigo". 

resonancias del Sur como espacio imaginario en la poética de Borges, en ambos relatos se alude a este punto cardinal en relación con el origen de los personajes, como marco del relato. Pero lo más llamativo es que se lo define por contraposición con otros espacios, con lo cual vuelve a advertirse el acento en esta concepción de frontera como idea convencional. El narrador expone las desventuras de "Funes" con el mismo recorrido de la mirada que en "Nuestro pobre individualismo", en donde la reflexión sobre nacionalismo y literatura parte de otros espacios (Inglaterra, Alemania...) para luego abordar las particularidades vernáculas :

Babilonia, Londres y Nueva York han abrumado con feroz esplendor la imaginación de los hombres; nadie, en sus torres populosas o en sus avenidas urgentes, ha sentido el calor y la presión de una realidad tan infatigable como la que día y noche convergía sobre el infeliz Ireneo, en su pobre arrabal sudamericano. (OC I : 490)

El espacio imaginario Sur, así, necesita su opuesto para definirse, mostrando, al mismo tiempo y de modo paradojal -gracias a la hipérbole-, que las diferencias tienden a igualarse en la comparación.

En el mismo sentido, creo que no resulta casual en el caso de "La forma de la espada" la elección del conflicto violento en Irlanda, territorio cuyos reclamos limítrofes contra Inglaterra son de larga data. En efecto, este personaje, aunque provenga de lo que para nosotros es el norte (Irlanda y luego Río Grande del Sur), rememora aquí cómo "Hondas descargas de fusilería conmovieron el Sur" (OC I : 493). Se atisba aquí cómo la alusión al "Sur" refiere a espacios de frontera, de orillas cuya delimitación resulta problemática.

Esta predilección por los espacios imaginarios fronterizos remite indefectiblemente a la célebre reflexión de Sarlo que da título al libro Borges, un escritor en las orillas. Se hace imperativo señalar que esta calificación emana especialmente del análisis de los tres primeros poemarios, es decir, del período que se conoce como Borges criollista o primer Borges. Cito un pasaje :

Borges trabajó con todos los sentidos de la palabra «orillas » (margen, filo, límite, costa, playa) para construir un ideologema que definió en la década del veinte y reapareció, hasta el final, en muchos de sus relatos. "Las orillas » son un espacio imaginario que se contrapone como espejo infiel a la ciudad moderna despojada de cualidades estéticas y metafísicas. Con el énfasis de su primer criollismo, provocador hasta en la ortografía, Borges escribe :

« Nuestra realidá vital es grandiosa y nuestra realidá pensada es mendiga. Aquí no se ha engendrado ninguna idea que se parezca a mi Buenos Aires, a este mi Buenos Aires innumerable que es cariño de árboles en Belgrano y dulzura larga en Almagro y desganada sorna orillera en Palermo y mucho cielo en Villa Ortúzar y proceridá taciturna en las Cinco Esquinas y querencia de ponientes en Villa Urquiza y redondel de pampa en Saavedra. [...] Ya Buenos Aires, más que una ciudá es un país y hay que encontrarle la poesía y la mística y la pintura y la religión y la metafísica que con su grandeza se avienen ».

[...] Borges libera a «las orillas » del estigma social que las identificaba. Lejos de considerarlas un límite después del cual sólo puede saltarse al mundo rural de Don Segundo Sombra, Borges se detiene precisamente allí y hace del límite un espacio literario. (Sarlo $1995: 52-54$ )

Estoy de acuerdo con Sarlo respecto de la continuidad del programa, aun en sus relatos, pero me permito enfatizar que, si bien el programa de dotar de imaginación los espacios de la patria se continúa, en esta etapa lo hace en otra dirección. De acuerdo a lo analizado 
en este trabajo, el juego con los límites de los espacios - la nación, de manera predilectase transforma en un artificio más del engranaje narrativo. Ya no se trata, como se desprende de la cita que recorta Sarlo de El tamaño de mi esperanza, de dotar de imaginación los contornos de la patria, sino de hacer ingresar esos límites imaginarios a la ficción y, desde ese territorio, interrogarlos hasta hacerlos tambalear.

Muchos de los procedimientos que analicé en los cuentos seleccionados se encuentran concentrados de manera más enfática en otros relatos del volumen. "Tlön, Uqbar, Orbis Tertius" ofrece la alegoría más evidente de un espacio imaginario, "La lotería en Babilonia" dialoga particularmente con el orden y sus posibilidades de concreción a los fines de regir una sociedad, "La biblioteca de Babel" es emblema del espacio como creación imaginaria convencional que se abisma por la expansión imaginaria de sus límites, mientras que "El milagro secreto" da cuenta de las posibilidades del tiempo imaginario de suspender y enviar a segundo plano al tiempo real, por citar sólo los ejemplos más claros. De este modo, se advierte la importancia de la invención como operación que genera realidades pasibles de ser compartidas por los lectores, tanto como las creencias que rigen nuestro contacto con el mundo real. Recordar, percibir, imaginar, soñar son las acciones privilegiadas en sus ficciones.

El principal mecanismo que intenté caracterizar en este análisis es el que el escritor mismo califica de "amplificación" y que consiste principalmente, en una primera instancia, en llevar a la práctica la combinación de los dos modos que puede asumir la "postulación clásica de la realidad" : por un lado, "imaginar una realidad más compleja que la declarada al lector y referir sus derivaciones y efectos" (OC I : 219); por otro, ejercer "la invención circunstancial" (OC I : 220), tomando en cuenta que "la imprecisión es tolerable o verosímil en la literatura, porque a ella propendemos siempre en la realidad" (OC I : 218). No otra es la clave de lectura que nos obsequia Stephen Albert en "El jardín de senderos que se bifurcan", que bien puede ser puesta a funcionar para todos los relatos del volumen: "Omitir siempre una palabra, recurrir a metáforas ineptas y a perífrasis evidentes, es quizá el modo más enfático de indicarla” (OC I : 479 ; énfasis en el original). En esta lectura, una entre tantas infinitas posibles, propongo que la palabra no dicha pero omnipresente, alrededor de la cual todas estas ficciones de la conjetura proliferan, es la de nación.

\section{BIBLIOGRAFÍA}

Alonso Estenoz, Alfredo. “The Words that Are not There: Chesterton in Borges's 'The Theme of the Traitor and the Hero". Variaciones Borges 32 (2011): 21-40.

Anderson, Benedict. Imagined Communities. Reflections on the Origin and Spread of Nationalism. London-New York : Verso, 1991.

Arrigucci, Dávi, Jr. "De la fama y de la infamia (Borges en el contexto literario latinoamericano), Cuadernos de recienvenido 10 (1999) : 18-47. http://dlm.fflch.usp.br/sites/dlm.fflch.usp.br/files/ recienvenido10.pdf Consultado el 26 de agosto de 2014 
Barrenechea, Ana María. “Borges entre la realidad y la historia”. España en Borges. Madrid: Ediciones El Arquero, 1990. 123-138.

Barrenechea, Ana María. La expresión de la irrealidad en la obra de Jorges Luis Borges y otros ensayos. Buenos Aires : Ediciones del Cifrado, 2000.

Balderston, Daniel. "Digamos Irlanda, digamos 1824. Para repensar la historia en Borges". Innumerables relaciones : cómo leer con Borges. Santa Fe : Universidad del Litoral, 2010. 102-118.

Balderston, Daniel. ¿Fuera de contexto ? Referencialidad histórica y expresión de la realidad en Borges. Buenos Aires : Beatriz Viterbo, 1996.

Balderston, Daniel. Timeline. <http://www.borges.pitt.edu/>

Bhabha, Homi. "Narrando la nación". La invención de la nación. Lecturas de la identidad de Herder a Homi Bhabha. Buenos Aires : Manantial, 2000. 211-219.

Blanco, Mariela. "Borges lector del nacionalismo". Actas Jornadas Internacionales "Borges lector". Buenos Aires : Biblioteca Nacional, 2014. http://www.bn.gov.ar/media/page/marielablanco.pdf Blanco, Mariela. "Invención de la nación en los primeros poemarios de Borges”. Variaciones Borges 35 (2013) : 143-161.

Borges, Jorge Luis. Inquisiciones. Madrid : Alianza, 2008.

Borges, Jorge Luis. El tamaño de mi esperanza/El idioma de los argentinos. Buenos Aires : Debolsillo, 2012.

Borges, Jorge Luis. Obras completas. 4 vols. Buenos Aires : Emecé, 1996.

Borges, Jorge Luis. Textos recobrados (1931-1955). Buenos Aires : Emecé, 2007.

González, José Eduardo. "Refractario al pensamiento : el hecho estético contra el Estado en

Ficciones". Jorge Luis Borges : Políticas de la literatura. Ed. Juan Pablo Davobe. Pittsburgh : IILI, 2008. 125-139.

Helft, Nicolás. Jorge Luis Borges. Bibliografía completa. Buenos Aires : FCE, 1997

Kaplan, Marina. “'Tlön, Uqbar, Orbis Tertius' y 'Urn Burial”, Comparative Literature 36.4 (1984) : $328-42$.

Sarlo, Beatriz. Borges, un escritor en las orillas. Barcelona : Ariel, 1995.

\section{NOTAS}

1. Arrigucci sintetiza de manera eficaz el valor de la invención como operación que orienta el modo de ficcionalizar de Borges a partir de un profundo análisis de "Biografía de Tadeo Isidoro Cruz" : "El cuento nace, en consecuencia, como una forma de lectura que implica una poética, una concepción del quehacer literario que transforma el nuevo texto en una especie de Ersatz, en un sucedáneo - o traducción - de un texto anterior del que es una versión conjetural desenmarañada de una red de otras versiones posibles. El nuevo texto es, pues, una especie de hallazgo, el objeto de una invención (término que se liga, como se sabe, a inventare, iterativo de invenire, hallar). Inventar es 'crear en la imaginación, urdir, contar de modo falso' y todas estas acepciones tomadas de un diccionario etimológico están contenidas en la poética de la lectura de Borges, tal como se configura aquí de modo ejemplar" (Arrigucci 1999: 39-40). Resulta particularmente productivo pensar la invención en Borges como mecanismo derivado de la facultad de 
imaginar. Respecto de la función de la imaginación, como parte integral del proceso cognoscitivo, es sugerente el vínculo que propone José Eduardo González con respecto a la filosofía de Kant (González 2008 : 135).

2. La misma Barrenechea relativiza su lectura anterior sobre el efecto irrealizador de los dispositivos narrativos de Borges en "Borges entre la eternidad y la historia" (Barrenechea 2000 : 303-321).

3. Ambos relatos fueron publicados en el diario La Nación. "Funes el memorioso", el 7 de junio y "La forma de la espada", el 26 de julio.

4. Esta confrontación entre el tono de la literatura uruguaya y la argentina ya había sido explorada en "Reverencia del árbol en la otra banda", ensayo de El tamaño de mi esperanza. La perspectiva se enfatiza aquí al resaltar el carácter "porteño", en oposición con el arraigo rural de Funes y, más indirectamente, con la poesía de Ipuche, lo cual Borges subraya aún con más énfasis en "La criolledad en Ipuche". El final de este texto juega con esta misma contraposición BorgesIpuche y, por transitividad, entre la literatura argentina y la literatura uruguaya : "Una confesión última. He declarado el don de júbilo con que algunas estrofas de Tierra honda endiosaron mi pecho. Quiero asimismo confesar un bochorno. Rezando sus palabras, me ha estremecido largamente la añoranza del campo donde la criolledad se refleja en cada yuyito y he padecido la vergüenza de mi borrosa urbanidad en que la fibrazón nativa es japenas ! una tristeza noble ante el reproche de las querenciosas guitarras o ante esa urgente y sutil flecha que nos destinan los zaguanes antiguos en cuya hondura es límpido el patio como una firme rosa" (Borges $2008: 65$ ).

5. Sarlo ofrece un análisis pormenorizado de la significación del sur como zona de conflictofrontera entre civilización y barbarie en el capítulo IV de su Borges, un escritor en las orillas (2001).

6. Sobre la importancia del secreto en la concepción de Borges de la historia, cf. Balderston 2010 : 44. El tema también es estudiado exhaustivamente en el artículo de Alfredo Alonso Estenoz (2011:32).

7. Agradezco a Daniel Fitzgerald, estudiante del posgrado de la Universidad Nacional de Mar del Plata, esta aclaración, así como el inestimable aporte de datos sobre la historia de Irlanda, imprescindibles para el armado de esta lectura.

8. Además del tinte conjetural que subyace al "digamos", se infiere un pacto que explicita la tan mentada "suspension of disbelief" que Borges cita en muchos de sus ensayos en relación con Coleridge. Su uso se repite en un ensayo posterior, pero muy vinculado con esta problemática, "El pudor de la historia", en el que se reflexiona sobre la conformación del discurso histórico. En este caso, la referencia temporal es menos ambigua, aunque presenta el mismo carácter azaroso ; es decir, como un ejemplo que sirve para demostrar la tesis o punto de partida. Así, "digamos, en 1225" (OC II : 133) no cuestiona la exactitud de la fecha, aunque sí su importancia o valor representativo, ya que la tesis del escrito es la convencionalidad de las fechas significativas de la historia : "yo he sospechado que la historia, la verdadera historia, es más pudorosa y que sus fechas esenciales, pueden ser, asimismo, durante largo tiempo, secretas" (OC II : 132).

9. Publicado primero en septiembre-octubre de 1952 en la revista Sur.

10. El homenaje a Berkeley es explícito en este texto a través de la invocación de su nombre asignado al general dueño de la quinta donde se refugiaron los independentistas "En aquel otoño de 1922" (OC I : 493).

11. La denominada "guerra civil", que sucede a la guerra por la independencia, como respuesta de algunos bandos disconformes ante el tratado, ya se inicia en junio de 1922. Si bien en el cuento se alude a la "guerra civil", se lo hace como parte de un futuro que, aunque inmediato, no coincide con las acciones referidas: "De mis compañeros, algunos sobreviven dedicados a tareas pacíficas; [...] otros (no los más desdichados), dieron con su destino en las anónimas y casi secretas batallas de la guerra civil" (OC I : 492). 
12. Este cuerpo militar estaba conformado, en su mayoría, por veteranos de la Primera Guerra Mundial, aunque también contó entre sus filas con miembros irlandeses. Su denominación proviene del color de sus uniformes.

13. Barrenechea propone una explicación respecto de esta preferencia por la frontera uruguaya como espacio privilegiado para situar sus ficciones: "Tanto él como otros compañeros de generación (Amorim, Ipuche) pensaban que el litoral y el Uruguay son más elementales que la pampa argentina y que la esencia de lo criollo se conserva en esas regiones más pura. El mismo amor al peligro que les hizo fijarse en la figura del compadrito, los llevó a buscar en Entre Ríos, el Uruguay y la zona fronteriza del Brasil el mítico lugar del coraje y la plenitud de la vida" (2000 : 29).

14. Lo que llamo espacios "entre" cobra una significación semejante a la que Homi Bhabha atribuye a los espacios "in between" para proponer una transformación de las fronteras que genere otros espacios instersticiales, de hibridación a partir de la inclusión de nuevos pueblos excluidos en pos de una "nueva cultura transnacional" (Bhabha $2000: 215-216$ ).

\section{RESÚMENES}

En este trabajo, se analizan cuentos de Ficciones -especialmente "Funes el memorioso" y "La forma de la espada"- en los que se advierte el modo en que Borges cuestiona el dispositivo ideológico de nación a partir de la construcción de "ficciones de la conjetura". El objetivo del análisis textual es demostrar que los procedimientos de desplazamiento, por medio de los que se mezclan datos reales e imaginarios, ponen en evidencia el carácter de invención de la idea de nación.

Cet article propose une analyse de quelques uns des contes de Ficciones -notamment "Funes el memorioso" et "La forma de la espada"- dans lesquels on constante la manière dont Borges conteste le dispositif idéologique du concept de nation en élaborant des "fictions de la conjecture". L'objectif de l'analyse textuelle est de démontrer que les procédés de déplacement, qui combinent des informations réelles et imaginaires, mettent en évidence que l'idée de nation est une question d'artifice.

In this paper we analyze stories from Ficciones - with particular emphasis on 'Funes el memorioso' and 'La forma de la espada' - wherein Borges questions the ideologeme of the nation via the elaboration of "conjectural fictions". We aim to show that the mechanism of displacement, the interplay of real and imaginary facts and details, and the texts' silences and omissions, all draw attention to the artifice inherent to the idea of the nation, to the nation as (an) invention.

\section{ÍNDICE}

Mots-clés: Borges, Ficciones, nation, invention, conjecture

Palabras claves: nación, invención, conjetura

Keywords: conjectural fictions 
AUTOR

MARIELA BLANCO

CONICET- Universidad Nacional de Mar del Plata

marielacblanco@yahoo.com.ar 